\title{
Modelo en red de los contenidos mediáticos en la era de los dispositivos inteligentes
}

\author{
Network model of media contents in the age of smartphones
}

\author{
Luis Fernando Morales Morante (1), Lluís MAs MANChón (2), Ruben Tous (3)
}

(1) Universidad Autónoma de Barcelona, Departamento de Publicidad, Relaciones Públicas y Comunicación Audiovisual, España, fernando.morales@uab.es (2) Universidad Pompeu Fabra, Departamento de Comunicación, España, Lluis.mas@upf.edu (3) Universidad Politécnica de Cataluña, Departamento de Arquitectura de Computadores, España, rtous@ac.upc.edu

\begin{abstract}
Resumen
Los cambios en las tecnologías de la información en las últimas décadas, representados por la democratización de Internet y la disponibilidad de las computadoras portátiles y dispositivos inteligentes están asociados con nuevos negocios y modelos comunicativos. La capacidad de los actuales teléfonos inteligentes facilita el procesamiento bidireccional y dinámico de grandes cantidades de contenidos. Los usuarios se agrupan en comunidades virtuales y se convierten en consumidores y productores: prosumidores. Estos contenidos se encuentran en la nube, en los medios de comunicación (plataformas), y se propagan rápidamente a través de la red. En este artículo se analiza la evolución de estos flujos de mensajes en el marco de las teorías que rodean el contenido generado por el usuario y la convergencia de medios. Se analiza también la naturaleza cíclica de la secuencia de datos, la evolución de los usuarios y la dependencia tecnológica para desarrollar y distribuir nuevos productos discursivos Se propone finalmente un modelo de flujos basado en algoritmos determinados por las preferencias personales de los usuarios
\end{abstract}

Palabras clave: Sociedad de la información. Contenido generado por el usuario. Tecnologías de la información. Teléfonos inteligentes. Redes de comunicaciones.

\section{Introducción}

Desde hace más de una década estamos inmersos en una sociedad dirigida por los nuevos medios o los medios sociales. Los medios tradicionales, las empresas e instituciones, los grupos y personas han vivido en un estado permanente de cambio tecnológico con grandes influencias sobre la producción e interacción de los contenidos. Es difícil prever el alcance de este nuevo escenario en el medio plazo. Esta revolución tecnológica hace que los contenidos mediáticos fluyan en diferentes entornos a través de sus usuarios en base a unos condicionantes técnicos, logísticos y sociales (Castells, 2012; Lee, Noh y Kim, 2012; Vásquez, 2013; García, 2015). Se precisan, pues, nuevos modelos comunicativos que expliquen una lógica de producción y consumo dominada por los dispositivos inteligentes cada

\begin{abstract}
The changes in the information technologies of the last two decades, represented by the democratization of the Internet and the availability of portable and intelligent handhelds, is associated with new business, communication and communicative models. The high service capacities of today's smartphones have enabled a two-way dynamic processing of great amounts of content. The users gather in virtual communities and become both consumers and producers of information: prosumers. These contents come from or are allocated in the cloud or other platforms, and spread rapidly through the net. In this paper, the evolution of information fluxes is analyzed in three phases of the Information Society or Net Society, and the theory around user-generated content and media convergence is discussed. Each phase is represented in a cyclical model articulating data dealing, the new roles of users and the impact of technology. On the basis of these models, news discourses and content may be anticipated for various purposes. A flow model based on algorithms determined by the personal preferences of users is finally proposed.
\end{abstract}

Keywords: Information society. User-generated content. Information technologies. Smart phones. Communication networks.

vez más automatizados en forma de pantallas móviles, portátiles o fijas, y con una capacidad de producción, distribución y consumo personales.

Particularmente, la total penetración social del teléfono inteligente, caracterizada por un desarrollo de las aplicaciones y el acceso a la alta velocidad en Internet, ha supuesto, por una parte, la concentración del resto de medios en un sólo dispositivo, y, por otra, grandes facilidades funcionales para la retroalimentación, reelaboración, diseminación y almacenamiento de mensajes. La gran visibilidad de la información producida y transmitida y la cantidad ilimitada de accesos para su visionado una vez almacenada, crea un producto fragmentario, conceptual y expansivo (Khoury, Jerez y De Cicco, 2008; Villegas y Álvarez, 2015). Un archivo cualquiera, difundido en un 
medio convencional, puede ser reelaborado, editado y distribuido en línea en función de múltiples criterios de producción: personal, lúdico, comercial, etc. Además, esta difusión puede provocar una reinterpretación de los contenidos, contribuyendo en ocasiones a una redistribución masiva y a un fenómeno de masas en sentido clásico. Se articula así el mensaje breve personal y unitario (Masip, 2008) con el diálogo múltiple de colectivos interconectados, tanto en formato texto, icónico o audiovisual (García-Cervigón, 2015; Rodríguez, 2015). Estos contenidos personales y colectivizados pueden llegar a tener desde usos muy específicos —-Instagram (Giménez, 2010)hasta usos masivos basados en forma de ocio.

Esta "eclosión masiva personalizada de los contenidos" (Urquiza, 2011) o auto-comunicación de masas (Castells, 2009) debe ser estudiada simultáneamente como tecnología y como contenido (Dylko y McCluskey, 2012). Los nuevos medios digitales y sociales plantean serios retos de investigación. Desde un punto de vista comunicativo, los conceptos, modelos y teorías se están adaptando a esta realidad. El paradigma de la comunicación unidireccional y masiva se ha visto sustituido por el paradigma de la interacción personalizada. Este fenómeno superestructural implica el planteamiento de nuevas líneas de investigación sobre las agenda de los medios (Vargo, Guo, McCombs y Shaw, 2014), los efectos de los contenidos (van Laer, de Ruyter, Visconti y Wetzels, 2014), la ética y la moral deslocalizadas o automatizadas (Johnson, 2015) o las estrategias comunicativas de marca (Maireder, Weeks, Gil de Zuñiga y Schlögl, 2015), entre otros. En todos los casos, se plantean nuevas concepciones de la comunicación. La gran dependencia tecnológica y el replanteamiento constante de los modelos clásicos exigen un planteamiento teórico y global sobre los nuevos modelos de producción, distribución y consumo de contenidos "mediáticos".

En este artículo, se desarrolla una propuesta que combina unos modelos teóricos sobre los flujos de comunicación y una explicación general desde el punto de vista técnico-práctico. Así, se parte del modelo de la auto-comunicación de masas y las estructuras en Red (Castells, 2009; Castells, 2011), se fundamenta teóricamente los rasgos de los nuevos usuarios de la comunicación (el contenido generado por el usuario) y se revisa el clásico fenómeno de la convergencia mediática, para intentar someter sus preceptos a la evolución prospectiva de la tecnología, que es el factor que dirige la actual revolución digital.

Se presentan además tres diagramas o modelos de flujos en los que pretendemos condensar la confluencia de las propuestas teoréticas y técnicas en las tres fases evolutivas de la actual sociedad de la información. Estos diagramas representan una primera aproximación a un modelo comunicativo integral que explique la forma en que la información se produce, distribuye, consume y reutiliza a través de estos dispositivos en la actualidad (Hall, 2011); y en el contexto de las recientemente denominadas Web Ciencia y Ciencia Red, entendidas como una interrelación de sistemas independientes (Tiropanis, Hall, Crowcroft, Contractor y Tassiulas, 2015).

\section{Sociedad red}

La sociedad de la información que Manuel Castells (2000) y Armand Mattelard (2002), entre otros, anticipaban y describían con gran detalle en el cambio de siglo es ya una realidad que se ha materializado en tres estadios diferenciados (Hall, 2011).

Con el nacimiento de las tecnologías de la información a principio de siglo, emergió el concepto de Sociedad Red, entendido como una interconexión de documentos a escala planetaria y en tiempo real mediante los motores de búsqueda y el correo electrónico, aunque con importantes limitaciones para el intercambio de materiales audiovisuales. La web 1.0 se desarrolló gracias al rápido incremento en las velocidades de descarga de datos por Internet, la democratización del $\mathrm{PC}$, el portátil y la rápida alfabetización digital de la población en ámbitos laborales, culturales y administrativos. El creciente intercambio de documentos de toda índole (se incorporan los audiovisuales) y la emergencia de los teléfonos y dispositivos inteligentes - usables e intuitivos-, desemboca progresivamente en una verdadera red de personas conectadas por criterios múltiples a través de distintas plataformas personales, sociales, culturales, laborales, políticas, íntimas... en lo que se ha venido a llamar web 2.0.

El componente comunicativo de estas redes ha forjado unas comunidades virtuales muy estables dentro de la estructura general de redes y en el seno de la sociedad. Se trata de una tendencia hacia la gestión automática inteligente de las redes según las necesidades de cada individuo a partir de la gran cantidad de datos disponibles de las diferentes comunidades (Anderson y Wolf, 2010). Esta red del futuro es la gestión inteligente del big data, también llamada web 3.0. En contraste con la Web 2.0, que se basa en la participación de los usuarios, la Web 3.0 incluye la interacción entre los objetos de la vida real que por lo general no se consideran entidades de computación (Stachowicz-Stanusch \& Wankel (2016). 
Esto supondrá una individualización de los contenidos de ficción en función de los perfiles personales recabados por los diferentes algoritmos.

El proceso de semantización que parte de la red primitiva y se desarrolla en la actualidad, responde a dos principios de funcionamiento de las redes, recogidos por Castells $(2011$, p. 774$)$ a partir de Grewal (2008). El primero es el volumen de la red o número de gente implicada en la comunidad. El segundo se refiere a la constante mutación de la red para adaptarse a sus integrantes al tiempo que excluye a los externos.

Las grandes redes globales en la actualidad ( $F a-$ cebook, Youtube, LinkedIn, Twitter...) han fomentado el asociacionismo múltiple de sus integrantes según criterios muy diferentes (sociales, culturales, laborales, geográficos, lingüísticos, nacionales, etc.), y que van Dijk (2009), al mencionar el Forrester Survey (Li, 2007, p. 11-12), reduce a entretenimiento, carrera y familia. En la medida en que una gran mayoría de la sociedad en los países desarrollados dispone de acceso constante e ilimitado a estas plataformas sociales, las comunidades virtuales han acogido a las antiguas comunidades sociales y se han reproducido según criterios múltiples y mutables. La tendencia es a crear red de redes capaces de absorber la vida real de la sociedad como un todo.

Siguiendo a la Network Gatekeeping Theory (Barzilai-Nahon, 2008), la pertenencia a una red depende de la producción y consumo significativo de los contenidos que produce (Castells, 2009, p. 417):

$[\ldots]$ power is primarily exercised by the construction of meaning in the human mind through process of communication enacted in global/local multimedia networks of mass communication, including mass self-communication.

Estos contenidos son mediatizados en la medida que existe una tecnología que determina el tipo de producción, distribución y recepción. Ahora bien, se trata de contenidos sustancialmente diferentes a los de los medios tradicionales. Aunque estos contenidos puedan ser producidos por agentes externos, todo el proceso está determinado por la construcción del significado que hará la comunidad en virtud de los criterios que la constituyen. Se produce así un fenómeno de filtro automático en el seno de la comunidad. Para identificar este filtro, es necesario identificar las fronteras de la red que dirigen las reglas del juego y del discurso (Nahon, 2011).

Así, las redes se configuran por alguna razón que da lugar al proceso dinámico de filtro y que determinará los criterios por los que sus integrantes harán comentarios, añadirán y editarán materia- les gráficos y audiovisuales, compartirán un artículo en prensa, etc. Este control depende de una suerte de auto conciencia grupal sobre la pertinencia de un comentario, información, enlace o foto en los derroteros del grupo, y se manifiesta mediante la aceptación, valoración, edición o re-producción de la información compartida. Por lo tanto, cada red "social" (o de cualquier índole) es solo una macro red que opera bajo grandes criterios de filtrado y que incluye miles de subredes multidimensionales cuya razón de ser son esos sub-filtros. Por tanto, los contenidos acaban diseminándose en la Red, pudiendo adoptar muy distintos significados y alcances, según las condiciones técnicas que configuran su distribución social y la interpretación particular del mensaje que van realizando los individuos que la conforman a lo largo de dicho proceso.

En suma, nos encontramos ante una estructura de redes que van del entorno más personal al más global. Dicha estructura existe en razón de múltiples criterios integradores, los cuales guían la producción e interpretación de sus contenidos.

\section{Contenido generado por el usuario}

El concepto de comunicación de masas ha sido superado por una conceptualización basada en el receptor, y pase a hablarse mejor de receptores cuyas necesidades e intereses solo necesitan las herramientas adecuadas para manifestarse y entablar contacto con otras personas y grupos. Conforme la tecnología fue haciendo posible una respuesta más real (inmediata, económica, sofisticada y precisa), el receptor se fue convirtiendo en receptor participativo hasta alcanzar funciones de recepción y emisión simultáneas (Jenkins, 2006).

El contenido generado por el usuario se refiere a la reelaboración que los receptores hacen de los contenidos mediáticos producidos por emisores institucionalizados o bien la elaboración de contenido original. Con la multiplicación de canales y el abaratamiento de las herramientas de producción, se ha pasado del concepto de audiencia al de usuario o consumidor; y con la emergencia de las redes, se ha pasado de hablar de participante o productor de contenidos a actor de una comunidad (en línea, virtual, mediática...). Esto ha dado lugar al término prosumidor como compendio entre consumidor y productor (Toffler, 1990; Villegas y Álvarez, 2015). La participación activa del usuario en la producción de la "información" (de cualquier género y tema) nace de la fusión entre la posibilidad técnica de producirla y la posibilidad social de compartirla repetidamente entre semejantes (García, 2015; Van Dijck, 2009). Esto crea una suerte de inteligencia productiva 
colectiva (Sunstein, 2006) porque los contenidos mutan permanentemente en función de la contribución de cada miembro como sucede por ejemplo con algunos modelos colaborativos como Wikipedia y los wikis. Los contenidos consumidos y producidos por los usuarios pueden ser de tres tipos:

- Contenidos preexistentes en muchas ocasiones enlatados para la Red: pueden ser desde contenidos clásicos de la televisión masiva emplazados en Youtube hasta pequeños fragmentos de programas en el streaming de la web de un conglomerado mediático.

- Contenidos creados ad-hoc por youtubers o influenciadores (influencers) de la red (network-making power): normalmente a través del seguimiento de grandes personalidades 0 entes en el seno de las redes.

- Contenidos producidos por los integrantes de la red: escrito, gráfico o audiovisual, con un dispositivo inteligente y con aplicaciones que le permiten compartirlo de forma inmediata.

Los nuevos usuarios de la comunicación son fuente de contenidos en sí mismos, pues los rasgos que los definen (criterios sociodemográficos, gustos, actitudes, valores...) son muy importantes para los gestores de redes, esto es, marcas, empresas o instituciones. Estos agentes intervienen en este proceso o bien dinamizando las redes ya existentes (switchers) o bien creando nuevas (network-making power) (Castells, 2011), dando lugar a una nueva lógica de funcionamiento entre los protagonistas del mercado: "the already close relationship between content producers, advertisers and consumers has become even more intimate" (van Dijck, 2009, p. 47).

En suma, las capacidades técnicas, los intereses económicos y las necesidades sociales constituyen el criterio marco para el "consumo y producción" de contenidos en la estructura de redes definida. El resultado es una socialización en red al servicio de los productos comunicativos que son producidos y consumidos en su seno. Esos productos dinamizan y hacen evolucionar una determinada red a partir de su contribución a su temática, esto es, a partir de su capacidad para ser: valorados - los "me gusta", los "participar", etc.; comentados y recomendados; editados o filtrados - compartidos, difundidos, enviados, etc.-; y producidos -en función del contenido anterior, que dará nuevamente las posibilidades para ser valorado, comentado, etc.-

Por tanto, recuperamos aquí el filtro como criterio de configuración de las "redes de usuarios". La constante generación de contenidos en las redes sociales, en lo que Dylko y McCluskey ha llamado "customización" de la información, define a los usuarios de estas redes y construye su (alter)ego en la realidad (Barzilai-Nahon, 2008).

\section{Convergencia mediática}

La crisis del modelo televisivo tradicional junto con la eclosión tecnológica y el desarrollo de Internet en el marco de Sociedad en Red antes mencionada han marcado un nuevo modelo convergente de medios y de actores de la comunicación (Vilches, 2013; Briggs y Burke, 2010). Los dispositivos actuales aportan funcionalidades múltiples en una plataforma personal y virtual aplicaciones específicas para la producción de mensajes de texto, imagen, sonidos, vídeo, almacenamiento interno y en nube, registro y edición de audio e imagen en alta definición-. Este fenómeno ha permitido modificar el modelo comunicativo e informativo unidireccional, propio de la televisión, la radio, la telefonía fija y celular. Gracias a estos dispositivos, el receptor se convierte en un agente activo del proceso de gestación e intercambio de nuevos contenidos digitales. Este cambio ha obligado a los distintos medios convencionales a reinventarse para competir en un nuevo mercado digital, más abierto, colaborativo y diversificado en sus funciones y tareas: el transmedia.

En 1990, Marsha Kinder fue la primera en emplear el término transmedia para definir la creación de un sistema de franquicias para la comercialización de historias de entretenimiento, donde los consumidores asumen el rol de productores de contenidos (Kinder, 1991). Años después, Henry Jenkins (2006) formula la teoría del storytelling (contenidos narrativos) mediante el proyecto de la nueva educación mediática. En ella, Jenkins defiende la importancia de la tecnología en la creación de historias de ficción y cómo el nuevo escenario mediático favorece el surgimiento de una cultura participativa, es decir, la cultura de la difusión y reelaboración constante, múltiple y bidireccional de los contenidos (Scolari, 2013). Desde el punto de vista teórico, Featherstone (2009) justifica plenamente la necesidad de disponer de un enfoque acerca de los medios de comunicación móviles. Diversos modelos intentan explicar de qué modo interactúan las plataformas y cómo las distintas tecnologías hacen posible ese flujo de datos a través de diferentes medios (Weedon et al., 2014; Suleman; Adams, 2013; Cotfas et al., 2013; Polson et al., 2013).

Este enfoque integrador tiene su primer antecedente en el término convergencia mediática y 
hace referencia a la fusión de plataformas digitales destinadas a la prestación de servicios de televisión por cable y satélite (Prado y Franquet, 1998). Cuando surge el "multimedia", Salaverría y García-Avilés (2008) articulan un modelo basado en cuatro dimensiones: empresarial, tecnológica, profesional y comunicativa, que incluye por primera vez al usuario dentro del proceso global de producción informativa. Estas dimensiones tuvieron una incidencia directa en el diseño de interfases de los medios de comunicación. Poco a poco se fueron creando las versiones en línea o web y se inicia un proceso de cambio profundo en la forma de dirigirse al público, consumir los contenidos y participar de un engranaje que finalmente acaba modificando el formato, estilo, sentido e impacto de los mensajes. La prensa escrita fue la primera en adecuarse al entorno web y complementar la información textual con archivos audiovisuales. Pronto, los canales de televisión tuvieron que ofrecer rápidamente contenidos en línea y a "la carta" para brindar una mayor visibilidad y flexibilidad a sus programas y evitar ser superados por plataformas como Youtube o Netflix. La radio acabó trazando un recorrido similar con la aparición de emisoras en streaming y archivos de podcast, al tiempo que, siguiendo el modelo de la televisión de pago, fue convirtiéndose en una alternativa para todos los gustos y países. De ello derivaron modelos de negocio de discografía en línea como Spotify o Deezer. Además, han surgido nuevas fórmulas narrativas y de negocio: relatos interactivos para ser consumidos a través de móviles como The Imp y Angus \& Cheryl (Morales, 2011) o historias que han emigrado de la televisión abierta hacia la web o viceversa como Enjuto Mojamuto (Morales y Hernández, 2012).

El usuario, por su parte, eleva cada vez más su nivel de intervención en los procesos y la gestación del contenido mediante una comunicación prácticamente bidireccional, gracias a la flexibilidad y potencia de las interfaces para producir, almacenar y distribuir mensajes por la Red de forma inmediata y a millones de receptores. Las tecnologías y las aplicaciones de uso masivo mediante las redes sociales no hacen sino potenciar las prácticas individuales y las acciones para realizar procesos productivos de distinto nivel de complejidad de forma rápida y barata. Y están sirviendo de base para nuevas experiencias interactivas y participativas en todos los niveles como Pandemic 1.0 de Lance Weiler, donde los usuarios participan directamente en la trama desde distintas plataformas. Asimismo, El Cosmonauta es una película de Riot Cinema Collective cuyo proceso de producción se plantea de forma totalmente colaborativa por Internet. Por su parte, el videojuego Assasins creed: revelations se desarrolla en su totalidad a través de las redes.

A nivel tecnológico, la estandarización de los sistemas operativos Android, iOS y Windows Phone, en móviles y tabletas ha permitido acceder a cientos de aplicaciones mediante tiendas virtuales. Apple, Windows, Google o Amazon ofrecen infinidad de recursos gratuitos y de pago capaces de capturar y recrear contenido digital en cualquier formato (Scolari, 2009; Shadbolt; Hall; Berners-Lee, 2006): texto (SMS, Whats'up, Telegram, Twitter y Line), archivos de imagen, llamadas múltiples con vídeo. En cuanto a fotografía e imagen fija, Instagram, DHQ Solutions, permiten retocar e incluir textos en fotografías y compartirlas por las redes sociales. Las aplicaciones para el tratamiento del sonido y el vídeo también son muy variadas: Vídeo editor o Trimmer son sólo algunos ejemplos. A través de ellas tenemos todo lo necesario para producir los contenidos y diseminarlos socialmente mediante grupos, foros y blogs especializados, prácticamente sin coste.

\section{Evolución de los modelos en red}

Detrás de la evolución de los flujos de contenidos mediáticos hay una serie de cambios tecnológicos clave. La lenta introducción de Internet y la web durante los años 90 propician la aparición de los primeros contenidos generados por usuarios, pero no es hasta el 2005 que se generaliza la producción mediática propia, y se produce la irrupción de la primera fase de la Web 2.0 (blogging, fórums, podcasting, primeras wikis y sitios de video/photo sharing). A nivel tecnológico, esta primera fase se caracteriza por: 1) una rápida expansión de los computadores personales (en junio de 2008 se alcanzó la cifra de mil millones a nivel mundial); 2) un incremento dinámico de la velocidad de cómputo (prácticamente doblándose cada dos años, manteniendo vigente la Ley de Moore) y la capacidad de almacenamiento; y 3) un incremento del ancho de banda (de los $128 \mathrm{~Kb} / \mathrm{s}$ de RDSI a los 0,25-20 Mbit/s de bajada del ADSL).

Desarrollamos el modelo gráfico a continuación del primer estadio de la comunicación en red, que llamaremos Interacción del usuario, presentando entre comillas los títulos de los cuadros del gráfico (véase "Análisis del caso 1"):

\subsection{Primer estadio: "Interacción del usuario"}

El usuario crea su propio contenido o lo recupera de la red y se dispone al intercambio de archivos con distintos fines: información, entretenimiento, persuasión, que son producidos partiendo de esa información textual en el marco de los diferentes 
softwares o plataformas de la web 2.0. Estos mensajes son subidos en webs, blogs o foros mediante Internet o son almacenados en discos duros para luego ser enviados a través del correo electrónico a usuarios individuales o grupalesmasivos. Este proceso comunicativo produce una interacción que acababa con una sencilla retroalimentación de la recepción o directamente sin respuesta alguna por parte de su creador:

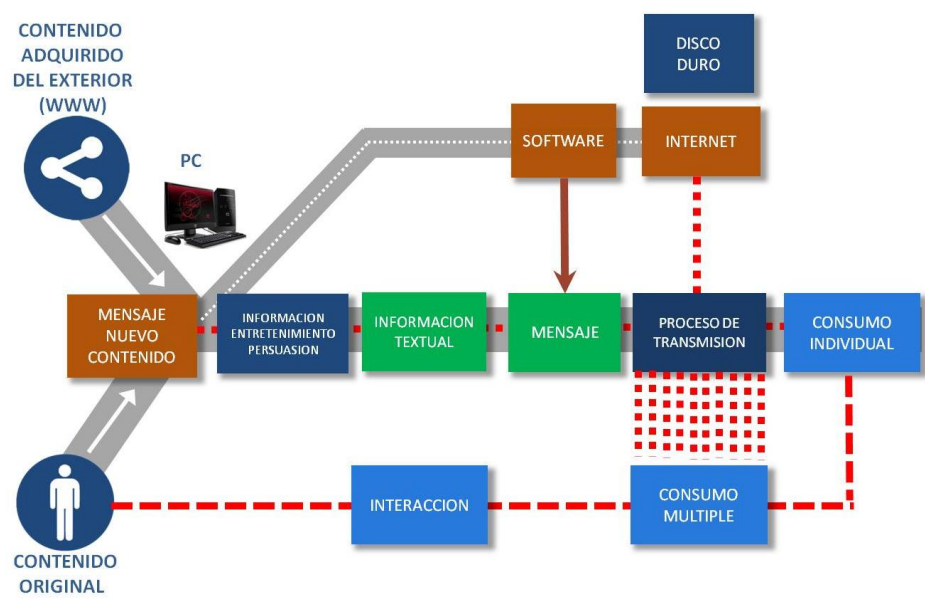

Figura 1. Análisis del caso 1: Interacción del usuario

5.2. Segundo estadio: "Contenido generado por el usuario (CGU)"

En una segunda fase de la Web 2.0 (2005-2010) toman protagonismo las redes sociales (Facebook), aparece el microblogging (Twitter) y se expanden los sitios para compartir imágenes y videos (YouTube, Flicker...). Esta etapa sigue ligada al computador personal, pero ahora se orienta preferentemente a los ordenadores portátiles en comparación a los ordenadores de mesa, por un aumento importante (de las conexiones inalámbricas) y los teléfonos móviles de segunda generación. Ambos tipos de dispositivos tienen funciones claramente separadas ya que la limitada capacidad de transferencia de datos de los celulares (80-100 kbit/s en celulares $2.5 \mathrm{G}$ ) hace poco atractivas las aplicaciones (navegación, multimedia, etc.). Sin embargo, el anterior éxito de los SMS indicaba que el futuro estaba en la portabilidad. En efecto, el final de la primer década del siglo se caracteriza por un espectacular incremento de la conectividad gracias al despliegue de redes $3 G$ (HSDPA permite una velocidad de bajada de hasta $14.0 \mathrm{Mbit} / \mathrm{s}$.) y a la generalización del acceso inalámbrico a conexiones de banda ancha desde prácticamente cualquier lugar.
Asimismo, se desarrolla intensamente el hardware destinado a los dispositivos móviles (microprocesadores de bajo consumo, etc.). Todo ello es el contexto ideal para que en 2007 Apple lance el primer iPhone, lo que representa el inicio de la era de los teléfonos inteligentes. Estos pequeños computadores multiplican y transforman el uso de las aplicaciones características de la web 2.0, gracias a nuevas prestaciones: 1) conectividad (banda ancha ubicua), 2) hardware (altas prestaciones de cómputo con bajo consumo, pantallas multitáctiles de alta resolución), 3) GPS, 4) fotografía digital de alta calidad y 5) espacio de almacenamiento prácticamente ilimitado (véase "Análisis del caso 2").

En este estadio el usuario es ahora plenamente consciente de la existencia de la "nube", por lo que utiliza cualquier contenido mediático como fuente de datos para la producción de mensajes. Los dispositivos inteligentes ahora son capaces de gestionar grandes cantidades de datos para la producción, difusión y comunicación de mensajes de texto mediante aplicaciones.

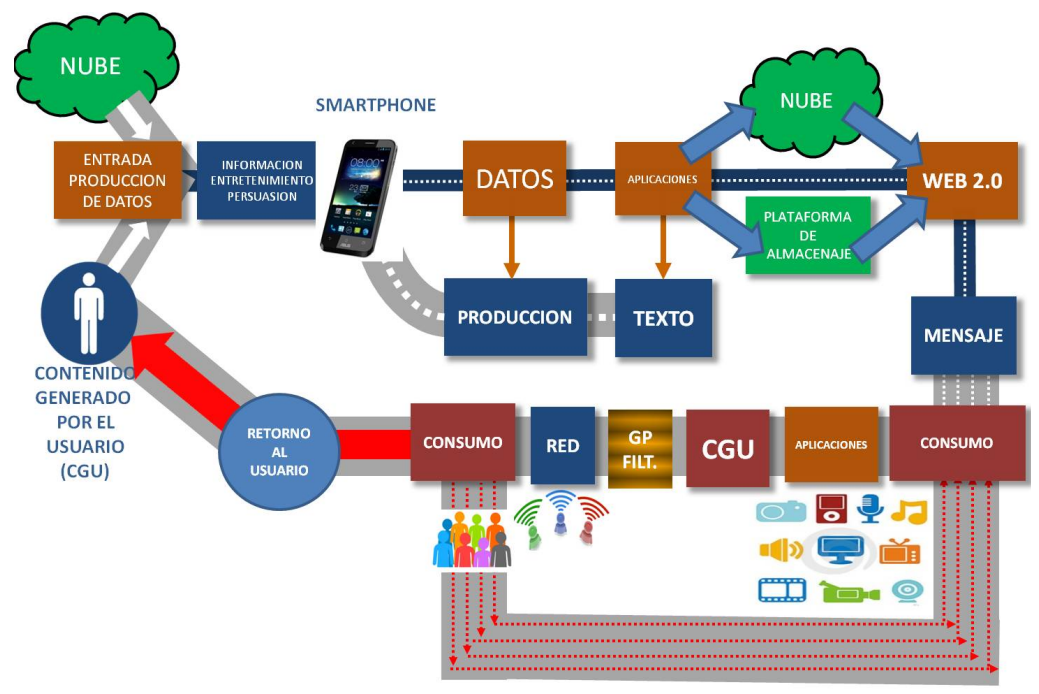

Figura 2. Análisis del caso 2: Proceso de comunicación del contenido generado por el usuario

Estos mensajes pueden ser almacenados en la plataforma o vuelven a la "nube"; en ambos casos, forman parte de la "Web 2.0", que se manifiesta como criterio de configuración de la comunidad de usuarios a los que se dirige el mensaje. En tanto ellos mismos (incluyendo el usuario original lo consumen y lo regeneren ("CGU") iterativamente (lo editan, comentan, valoran, reordenan, manipulan, rehacen, copian, imitan...) con aplicaciones en el marco de la "red" de forma cooperativa y en bucle. Todas estas operaciones no se producen de una vez, sino a medida que el 
mensaje es difundido socialmente en una determinada comunidad o red de usuarios. En cualquier caso, este contenido en proceso siempre puede volver a formar parte de la nube y entra en el bucle de otras redes diferentes o de nivel más alto o más bajo (Figura 2, en la página anterior).

\subsection{Tercer estadio: "Sociedad de la comunicación inteligente (SCl)"}

El desarrollo y uso de aplicaciones para dispositivos inteligentes ha alcanzado en la actualidad un ritmo frenético (en julio de 2013, la plataforma de distribución de aplicaciones para dispositivos inteligentes Google Play superó el millón de aplicaciones y un total de más de 50.000 millones de descargas (Phone Arena, 2013). La evolución tecnológica de los dispositivos, la computación en la nube (Amazon Web Services, etc.) y los ecosistemas tecnológicos creados por las grandes compañías (los mercados de aplicaciones, entornos de desarrollo, el sistema operativo Android) ofrecen las condiciones más favorables para la expansión de los dispositivos inteligentes y sus aplicaciones.

El volumen de contenidos según el modelo anterior se multiplica muy rápidamente. El $90 \%$ de los datos de que disponemos se han generado solo en los dos últimos años. Su explotación discriminada, inteligente, semántica, es lo que se conoce como análisis Big Data. Sin embargo, no resulta sencillo realizar predicciones para el futuro en un contexto tan dinámico. La evolución tecnológica de los dispositivos inteligentes se caracteriza por: 1) una mejora de la conectividad (mayor ancho de banda y cobertura); 2) mejores pantallas y nuevas formas de interacción hombre-máquina; 3) mejores baterías y menor consumo; y 4) almacenamiento mayor, más rápido y más barato. En este sentido, los head-mounted displays (HMD, e.g. Google Glass), los wearables (smartwatches, smartbands), Internet of Things (IoT), la robótica avanzada (los chatbots), los vehículos autónomos o los drones, forman parte de la red semántica o inteligente (web 3.0), caracterizada por redes de usuarios que conforman sistemas funcionales inteligentes integrados en las actividades del ser humano, para lo que se desarrolla incesantemente la miniaturización y automatización de gadgets y la interacción hombre-máquina. Por tanto, este tercer estadio se caracteriza por unos flujos de datos permanentes vinculados al día a día del usuario gracias a una total conexión de información y contenidos desde la "nube", y disponiendo de una mayor calidad y velocidad de señal ("datos") en el dispositivo inteligente.
En el futuro, los dispositivos inteligentes se habrán integrado totalmente en el usuario en sus diferentes actividades rutinarias, siendo capaz de interactuar con sistemas automáticos mientras se lleva a cabo cualquier otra tarea. Las aplicaciones se están convirtiendo en la herramienta para recrear un contenido recibido o visualizarlo a través de los dispositivos. Esto hace que los diferentes actores del proceso operen sobre la base de los contenidos disponibles o bien produzcan contenido de texto nuevo mediante las aplicaciones para generarlo o editarlo. Por tanto, a diferencia del CGU, donde podíamos definir más fácilmente los roles y localización de los actores del proceso de producción de contenidos, en la $\mathrm{SCl}$ estos se vuelven evidentemente más difusos y ciertamente intercambiables. El usuario desempeña simultáneamente la función "productor" y la función de "consumidor" de información textual generada por otros participantes del proceso - parte inferior de la figura-como receptor y como eslabón de la cadena de sentido.

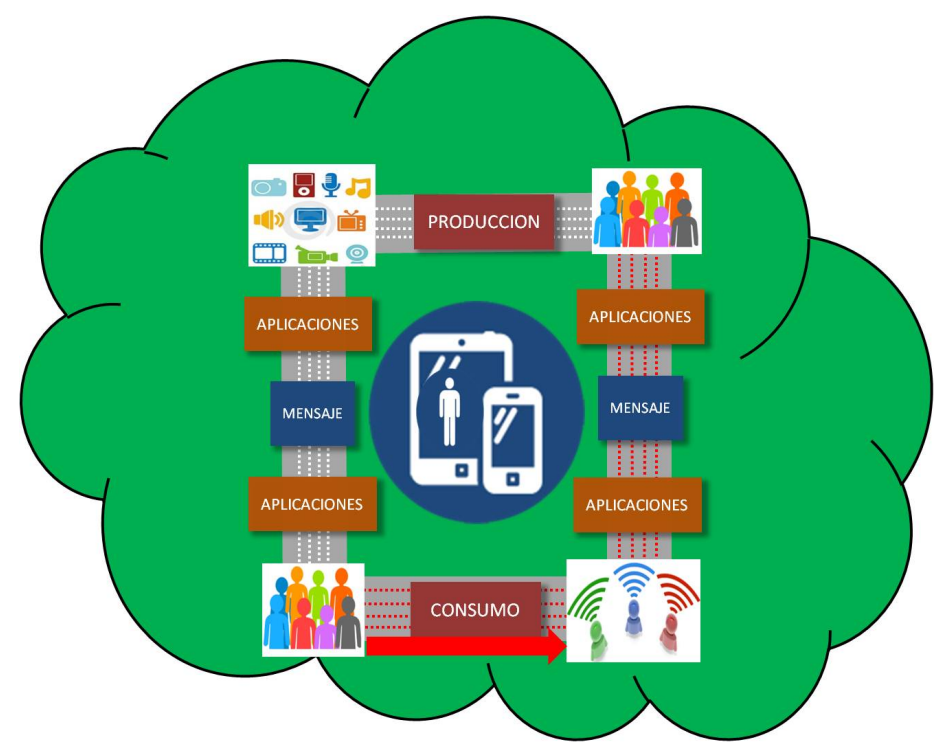

Figura 3. Análisis del caso 3: Sociedad de la comunicación inteligente (SCI)

Esto se visualiza en los dos niveles de flujo que se interconectan mediante las aplicaciones como canales de envío del mensaje o como datos de un nuevo relato en cualquier formato: texto, imagen, sonido, vídeo o combinación de todos de forma individual o colaborativa (crossfunding), y su posterior envío a otros usuarios o posibles productores reelaboradores - parte superior de la figura-. Por tanto, nos encontramos ante un proceso continuo de circulación de mensajes originales, adquiridos o nuevos (reelaborados) por los diferentes usuarios que hacen que el mensaje sea recibido y posteriormente recreado por otros 
usuarios partícipes de la red o por el grupo que los introduce intencionadamente en el circuito.

En este escenario podemos hablar de una comunicación constante e inteligente, que va más allá de las funciones y roles estables del proceso tipificado en las fases anteriores. La figura del gatekeeper se relativiza, porque el mensaje se disemina con mucha más, rapidez y puede expandirse por otras redes de usuarios que operan simultáneamente. Este mensaje puede ser por tanto recibido y reelaborado iterativamente por los usuarios vinculados a la red primaria original.

Visto de forma amplia, este modelo de flujos es capaz de hacer realidad la gestión e interacción del individuo con otros individuos, grupos sociales, administraciones (gestiones) u otros entes abstractos, y con los sistemas automáticos que gobiernan las diferentes rutinas: las ciudades inteligente (optimización de las agendas, gestión del tráfico, clima, optimización de rutas...), casas inteligente (alarmas, electrodomésticos, etc.), entornos virtuales de trabajo... La web 3.0 es la interconexión inteligente de todos los datos que definen nuestra vida al servicio de los sistemas en los que nos integramos inevitablemente o de forma voluntaria y que sirven a nuestros "intereses" de forma inteligente o significativa (semántica).

\section{Conclusiones}

Este artículo intenta modelizar la evolución de la distribución de contenidos mediáticos en la era digital. Se proponen dos fases, más una tercera que comienza a instaurarse. De forma específica, nos hemos centrado en el receptor como núcleo de los procesos de comunicación de acuerdo al cambio de paradigma observado por Manovich (2001): del broadcasting o la comunicación masiva a la comunicación personalizada. El primer diagrama explica la conversión progresiva de un receptor tradicional en un usuario nativo digital. El segundo diagrama se ha caracterizado por una socialización a escala mundial y en todos los ámbitos vitales, lo que ha llevado a la masificación personalizada de los contenidos mediáticos según la nueva lógica en red. Y la tercera fase añade la gestión inteligente y automática de los datos de la red al servicio de usuarios totalmente individualizados. En la primera fase, Internet fue el agente del cambio, en la segunda el dispositivo inteligente y en la tercera tomarán protagonismo los dispositivos automáticos integrados, sea en forma de gafas, chips incorporados a nuestro cuerpo, sistemas de navegación inteligentes orales, robots de todo tipo, sistemas de navegación incorporados a los medios de transporte, etc.
Este artículo explora de forma teórica la doble perspectiva (comunicativa y técnica) planteada por Hall (2011), quien concibe la evolución de la red en tres estadios. La aproximación prospectiva a un modelo comunicológico actual precisa una revisión teórica tanto desde las propuestas más sociales o humanas como desde la propia tecnología de la información. En línea con Dylko y Mccluskey (2012), sólo así podremos establecer estrategias empresariales, políticas, socioculturales o incluso científicas. Y sólo así se pueden generar nuevos ámbitos de estudio. En particular, las futuras líneas de trabajo en esta área deberán seguir las líneas siguientes: la calidad y los estándares informativos de productos producidos en alguna de sus fases o en todas ellas por agentes no institucionalizados, las corrientes de opinión (agenda) y los frames creados por esta nueva realidad mediática, la formación de comunidades virtuales, las estrategias de marcas en las redes sociales, o cuestiones morales y éticas según el riesgo percibido, la aceptación de la tecnología y la atribución de responsabilidad (cuando se produzcan graves crisis) en un contexto en que la mayoría de agentes en la red son autómatas, y en el que la producción, distribución e incluso consumo de contenidos esté dominado por estos sistemas.

Se precisa por tanto pensar la nueva sociedad de la comunicación a partir de los contenidos mediáticos que la vehiculan, con el objetivo de fomentar una mayor eficiencia en el interés general de todos. La acumulación de conocimiento en torno a los flujos comunicativos actuales y del futuro puede tener importantes aplicaciones sociales, económicas, culturales, morales...

Naturalmente, conviene aplicar diseños metodológicos diferentes a los convencionales para poder estudiar esta interacción bidireccional y dinámica entre usuarios. Y poder construir teorías comunicativas que expliquen estos nuevos procesos. Este trabajo de tipo ensayístico sólo sirve para apuntar hipótesis de trabajo y variables relevantes del problema de conocimiento. Sin embargo, en la actualidad, se precisan iniciativas capaces de acotar nuevos problemas y nuevos objetos de estudio. En este sentido, el paradigma de los efectos de los medios sigue siendo aplicable en la actualidad, aunque teniendo en cuenta las nuevas formas que toma el mensaje en función de las nuevas condiciones de recepción. Ya no se trataría tanto de un proceso uni o bidireccional, sino de un proceso basado en la interacción automatizada de sus usuarios, partiendo de un mensaje iniciático controlado y midiendo los efectos perceptivos y sociales que se producen conforme avanza dicha interacción. 


\section{Referencias}

Amazon Web Services. https://aws.amazon.com/es/ (201608-10)

Anderson, Ch.; Wolff, M. (2010). The Web is dead. Long live the Internet. // Wired Magazine. 18.

Barzilai-Nahon, K. (2008). Toward a theory of network gatekeeping: A framework for exploring information control. // Journal of the American society for information science and technology. 59:9, 1493-1512.

Briggs, A.; Burke, P. (2010). Social history of the media: From Gutenberg to the Internet. Polity.

Castells, M. (2012). El poder en la era de las redes sociales. Nexos. http://www. nexos. com.mx (2012/11/11).

Castells, M. (2011). The rise of the network society: The information age: Economy, society, and culture. John Wiley \& Sons.

Castells, M. (2009). Comunicació i poder (Vol. 14). Barcelona: Editorial UOC.

Cotfas, L.; Ioan R. (2013). Adaptable Alternate Reality Games Platform. // Journal of Mobile, Embedded and Distributed Systems. 5:4, 130-135.

Dylko, I.; McCluskey, M. (2012). Media Effects in an Era of Rapid Technological Transformation: A Case of User-Generated Content and Political Participation. // Communication Theory. 22:3, 250-278.

Featherstone, M. (2009). Ubiquitous media. // Theory, Culture \& Society. $26: 2-3,1$

García, G. (2015). Convergencia de medios y nuevas formas de comunicación. // Revista Politécnica. 9:16, 117-130.

García, J. (2015). Cuando el 15M envejeció a los medios de comunicación: emergencia de prosumidores y desarrollo de nuevos modelos mediáticos. Julio, Agosto y Septiembre, 2015. 9.

García-Cervigón, A. (2015). El lenguaje de los chats. Un nuevo léxico en la Red 4:33.

Giménez, D. (2010). Redes sociales: posibilidades de Facebook para las bibliotecas públicas. // BiD: textos universitaris de biblioteconomia i documentació 24:5. (2015). http://bid.ub.edu/24/garcia2.htm (2015-12-10).

Grewal, D. (2008). Network power: The social dynamics of globalization. Yale University Press.

Hall, W. (2011). Network Theory The Ever Evolving Web: The Power of Networks. // International Journal of Communication 5:14. http://ijoc.org/index.php/ijoc/article/view Article/1120 (2015-08-25).

Jenkins, H. (2006). Convergence culture: Where old and new media collide. NYU press.

Johnson, D. (2015). Technology with No Human Responsibility?. // Journal of Bussiness Ethics, 127, 707-715.

Khoury, J.; Jerez, H.; De Cicco, L. (2008). Design and implementation of a framework for persistent identification and communication in emerging networks. // Proceedings of the 4th International Conference on Testbeds and research infrastructures for the development of networks \& communities. ICST (Institute for Computer Sciences, Social-Informatics and Telecommunications Engineering), 2008.

Kinder, M. (1991). Playing with power in movies, television, and video games: from Muppet Babies to Teenage Mutant Ninja Turtles. Univ of California Press.

Lee, S.; Noh, Mi.; Byung Gon, K. (2012). An integrated adoption model for mobile services. // International Journal of Mobile Communications. 10:4, 405-426.
Li, Ch.; et al. (2007). Social technographics: Mapping participation in activities forms the foundation of a social strategy. Forrester Research.

Maireder, A.; Weeks, B.; Gil de Zuñiga, H.; Schlögl, S. (2015). Big Data and Political Social Networks: Introducing Audience Diversity and Communication Connector Bridging Measures in Social Network Theory. // Social Science Computer Review, 1-16.

Manovich, L. (2001). The Language of New Media. The MIT Press: London.

Masip, P. (2008). Internet a les redaccions. // Barcelona: Trípodos.

Mattelart, A. (2002). Geopolítica de la cultura. Lom Ediciones.

Morales, F. (2011). Migración hacia nuevas pantallas: transformaciones estéticas, narrativas en los productos de ficción para telefonía móvil y dispositivos personales en España. // Observatorio $\left(\mathrm{OBS}^{*}\right)$. 5:1, 103-121. http://ddd.uab.cat/record/105699 (2016-07-16).

Morales, F.; Hernández, P. (2012). La webserie: convergencias y divergencias de un formato emergente de la narrativa en Red, // Revista: Comunicación, Universidad de Sevilla. 10:12, 140-149. https://dialnet.unirioja.es/ser vlet/articulo?codigo=3953638 (2016-07-16).

Nahon, K. (2011). Network Theory| Fuzziness of Inclusion/Exclusion in Networks. // International Journal of Communication. 5, 756-772.

Phone Arena (2013). http://www.phonearena.com/news/Pho neArena-Awards-2013-Best-Smartphones_id50069 (2016-08-14).

Polson, D.; Maguire, R.; Selin, C.; Cook, A. (1998). The MultiPlatform User Engagement and Data Visualisation Tool.

Prado, E.; Franquet i Calvet, R. (1998). Convergencia digital en el paraíso tecnológico. // Zer: revista de estudios de comunicación= komunikazio ikasketen aldizkaria. 3 .

Rodríguez, F.; Cortazar, F. (2015). Ciberrelaciones: amistad, amor, y sexo en los salones de chat. // Comunicación y Sociedad. 34. http://revistascientificas.udg.mx/index.php/ comsoc/article/view/1962 (2016-08-14).

Salaverría, R.; García-Avilés, J. A. (2008). La convergencia tecnológica en los medios de comunicación: retos para el periodismo.

Scolari, C. (2013). Media Evolution: Emergence, Dominance, Survival, and Extinction in the Media Ecology. // International Journal of Communication. 7, 1418-1441.

Scolari, C. (2009). Alrededor de la (s) Convergencia (s) 1: Conversaciones Teóricas, Divergencias Conceptuales y transformaciones en el ecosistema de medios. // Signo y Pensamiento. 28:54, 44-55. http://www.scielo.org.co/ scielo.php?script=sci_abstract $\&$ pid $=$ S0120-4823200900 0100003 (2016-08-14).

Shadbolt, N.; Hall, W.; Berners-Lee, T. (2006). The semantic web revisited. // Intelligent Systems, IEEE 21:3, 96-101.

Stachowicz-Stanusch, A.; Wankel, C. (2016). Emerging Web 3.0/semantic Web Applications in Higher Education: Growing Personalization and Wider Interconnections in Learning. Charlotte, North Carolina: Information Age Publishing.

Suleman, M.; Adams, B. (2013). Redesigning the Story: Liberating Narrative from Form Using Organic Transmedia Storytelling.

Sunstein, Cass R. (2006). Infotopia: How many minds produce knowledge. Oxford University Press.

Tiropanis, Thanassis; Hall, Wendy; Crowcroft, Jon; Contractor, Noshir; Tassiulas, Leandros (2015). Network science, web science, and internet science. // Communications of the ACM. 58:8, 76-82.

Toffler, A. (1990). Future shock. New York: Bantam Books. 
Urquiza, R. (2011). Redes, dispositivos y aplicaciones: la simbiosis y economía de la convergencia. // Razón y palabra. 77, 52. https://dialnet.unirioja.es/servlet/articulo? codigo=3829923 (2016-08-14).

Van Dijck, J. (2009). Users like you? Theorizing agency in user-generated content. // Media, culture, and society. $31: 1,41$.

Van Laer, T.; de Ruyter, Ko; Visconti, L.; Wetzels, M. (2014). The Extended Transportation-Imagery Model: A MetaAnalysis of the Antecedents and Consequences of Consumers' Narrative Transportation. // Journal of Consumer research. 40:5, 797-817.

Vargo, Ch, J.; Guo, L.; McCombs, M.; Shaw, D. (2014). Network Issue Agendas on Twitter During the 2012 U.S. Presidential Election. // Journal of Comunication. 64, 296316 .

Vázquez, A. (2013). Poder y transmedia en la sociedad red: el transpoder mediático. // Razón y palabra. 83, 331-359. https://dialnet.unirioja.es/servlet/articulo?codigo $=50$ 73979 (2016-08-14).
Vilches, L. (2013). Convergencia y transmedialidad: La ficción después de la TDT en Europa e Iberoamérica. Barcelona: Gedisa.

Villegas, J.; Álvarez, J. (2015). Cambios en los patrones de consumo entre los estudiantes de periodismo: de prosumidores mediáticos a profesionales de la información. // Estudios sobre el Mensaje Periodístico. 21:1, 615-628. http://search.proquest.com/openview/4cc6337d53b53262b16b5a7fbcde5d01/1?pqorigsite=gscholar\&cbl=55463 (2016-08-14).

Weedon, A.; et al (2014). Crossing media boundaries Adaptations and new media forms of the book. // Convergence: The International Journal of Research into New Media Technologies. 20:1, 108-124.

Enviado: 2016-05-02. Segunda versión: 2016-07-12 Aceptado: 2016-09-15. 